\title{
Endogenous Abscisic Acid in Barley and Use of Abscisic Acid in Malting
}

\author{
Katsuhiko YAMADA \\ Brewing Science Laboratory, Kirin Brewery Co., Ltd., \\ Takasaki, Gunma, 370-12, Japan
}

Received July 18, 1984

\begin{abstract}
In order to obtain information for preparation of good quality malt, changes in endogenous abscisic acid (ABA) in barley during malting were studied. When barley was steeped aerobically, the ABA level in the barley kernel greatly decreased. The activity level of the ABA metabolic system linked to the start of germination was estimated. The level of ABA increased during the germination stage with the development of each embryonic organ. On the basis of these results, the effects on malt quality of $\mathrm{ABA}$ plus gibberellic acid $\left(\mathrm{GA}_{3}\right)$ added to barley during malting were examined. With appropriate combinations of $\mathrm{ABA}$ and $\mathrm{GA}_{3}$, malt with good quality was obtained in high yield.
\end{abstract}

When barley starts germination, various hydrolytic enzymes are produced and secreted into the endosperm, resulting in decomposition of its components. Induction or activation of these enzymes during germination of barley is thought to be controlled by the balance of 4 kinds of plant hormones ${ }^{1,2)}$ : gibberellin, abscisic acid, auxin, and cytokinin. The effects of gibberellin have been known for a long time and studied extensively. ${ }^{3 \sim 6)}$ I reported earlier that the dominant gibberellin secreted during germination of barley is $\mathrm{GA}_{1}$, with $\mathrm{GA}_{3}$ being a minor gibberellin, and that the levels of these gibberellins in barley change during malting. ${ }^{7)}$ There seem to be no other reports on the behaviour of endogenous plant hormones in barley kernels during malting. Therefore, I focused attention on abscisic acid (ABA), which has a physiological activity opposite to that of gibberellin, and examined changes in the level of endogenous ABA in barley during malting. The effects on germination and malt quality of adding ABA in combination with $\mathrm{GA}_{3}$ to barley during malting were also studied, and a new technique was developed for obtaining good quality malt by the addition of ABA. The significance of changes in the ABA level during steeping and germination of barley is also discussed.

\section{MATERIALS AND METHODS}

Barley samples. Two varieties of two row malting barley (Hordeum disticum L. emend, LAMARK) were used: Betzes, imported from Canada (1979), and Fuji Nijo II, cultivated in Yamanashi Prefecture (1979). Samples were graded and kernels remaining on a $2.5 \mathrm{~mm}$ sieve were used.

Authentic $A B A$ and $G A_{3}$. Authentic ( \pm$)-(2 Z, 4 E)-$ abscisic acid (ABA) and gibberellic acid $\left(\mathrm{GA}_{3}\right)$ were purchased from Tokyo Kasei Co., Ltd.

Malting. Malting was done in our malting plant as follows: Portions of $1 \mathrm{~kg}$ of barley in a stainless steel cage were steeped for alternating periods of $6 \mathrm{hr}$ in water and in air at $14^{\circ} \mathrm{C}$ until the moisture content reached $41 \sim 43 \%$. After steeping, the cages were transferred to a germination box and germination was continued for 6 days by the method I described previously. ${ }^{7)}$ Kilning was carried out by the prescribed method. ${ }^{8)}$ In studies on changes in the level of endogenous ABA, green malts were subjected to analysis.

Extraction and purification of endogenous $A B A$ from barley and malt.

Extraction. Samples ( $100 \mathrm{~g}$ of barley or malt, $200 \mathrm{~g}$ of green malt) were homogenized in $500 \mathrm{ml}$ of $80 \%$ acetone with a Polytron (type PT 20 ST “OD” SM, Kinematica G.m.b.H., Switzerland). The homogenate was shaken for $3 \mathrm{hr}$, left overnight at $8^{\circ} \mathrm{C}$ in the dark, and then centrifuged 
for $15 \mathrm{~min}$. The clear supernatant obtained was combined with three supernatants obtained by repeated re-extraction of the residue with $50 \mathrm{ml}$ of $80 \%$ acetone. This solution was then subjected to solvent extraction, and the ethyl acetate-soluble acidic fraction was obtained as described in my previous paper. ${ }^{7)}$

Sephadex LH-20 column chromatography. The acidic fraction was dissolved in a small volume of acetone $(2 \sim 3 \mathrm{ml})$, placed on a column $(25 \mathrm{~cm} \times 1.7 \mathrm{~cm}$ in diameter $)$ of Sephadex LH-20 (Pharmacia Fine Chemicals AB, Sweden) and eluted with acetone. The eluate $(40 \sim 165 \mathrm{ml})$ was collected and the solvent was removed in vacuo.

Silicic acid partition column chromatography. The materials separated by Sephadex LH-20 column chromatography were purified on a column $(1.4 \times 10 \mathrm{~cm})$ made of $8 \mathrm{~g}$ silicic acid impregnated with $5 \mathrm{ml}$ of $0.5 \mathrm{~m}$ aq. formic acid which had been saturated with $10 \%$ EtOAc in hexane. Hexane-EtOAc mixtures saturated with $0.5 \mathrm{~m}$ formic acid were used for elution with stepwise increase of EtOAc contents. After elution with $25 \mathrm{ml}$ of $10 \%$ EtOAc in hexane, the eluate with $50 \mathrm{ml}$ of $40 \%$ EtOAc in hexane was collected.

Preparative thin-layer chromatography. The materials obtained by partition column chromatography were streaked in a $12 \mathrm{~cm}$ band on a silica gel 60 F254 plate $(20 \times 20 \mathrm{~cm}, 2 \mathrm{~mm}$ thickness, Merck, Germany). On both sides of the band, appropriate amounts of authentic ABA were spotted to give guide spots. After development with chloroform-acetic acid $(96: 4)$, the zone corresponding to ABA was scraped off and extracted with methanol.

Thin-layer chromatography. The residual matter separated by preparative thin-layer chromatography was applied to a silica gel $60 \mathrm{~F} 254$ plate $(20 \times 20 \mathrm{~cm}, 0.25 \mathrm{~mm}$ thick) with a concentration zone (Merck, Germany) as for preparative chromatography. The plate was developed with toluene-EtOAc-acetic acid $(30: 10: 2)$. The zone corresponding to ABA was scraped off the plate and extracted with methanol. After methanol was removed from the extract in vacuo, the residue was dissolved with $2 \mathrm{ml}$ of acetone, and $50 \mathrm{ml}$ of water of $\mathrm{pH} 2.5$ (acidified with $10 \%$ phosphoric acid) was added. The resultant solution was extracted 5 times with ethyl acetate to give the ABA fraction. The solvent was removed in vacuo after drying over anhydrous sodium sulfate.

Determination of $A B A$. After methylation of the purified fraction with diazomethane, ABA methyl ester was measured by the method of Seeley ${ }^{9}$ in a GC-3BE gas chromatograph (Shimadzu Ltd., Japan) equipped with an electron-capture detector. A glass column $(1.7 \mathrm{~m} \times 3 \mathrm{~mm}$ in diameter) packed with $2 \%$ SE-30 on Gas-Chrom $Q$, $60 / 80$ mesh, was used with nitrogen as the carrier gas at a flow rate of $90 \mathrm{ml} / \mathrm{min}$. The column and injection temperatures were 175 and $205^{\circ} \mathrm{C}$, respectively. No correction was made for losses of ABA during the assay.
Analysis of malt. Malts were analyzed by the methods given in Analytica-EBC. ${ }^{10)}$

Bioassay of $A B A$. The biological activity of the purified fraction corresponding to ABA was examined by the method of Murakami ${ }^{11)}$ with dwarf rice seedlings (var. Tan-ginbozu).

Combined GC-MS. GC-MS was performed with a Hitachi M-80 equipped with a data processer type M-003. A glass column $(1 \mathrm{~m} \times 3 \mathrm{~mm}$ in diameter $)$ packed with $2 \%$ OV-1 on Chromosorb W (AW-DMCS), 80/100 mesh, was used with helium as the carrier gas at $1.2 \mathrm{~kg} / \mathrm{cm}^{2}$. Column and injection temperatures were 165 and $200^{\circ} \mathrm{C}$, respectively. The ionizing voltage was $20 \mathrm{eV}$ and the accelerating voltage was $3 \mathrm{kV}$.

\section{RESULTS AND DISCUSSION}

\section{Identification of endogenous $A B A$ and accuracy of determination}

The biological activity of the ABA fraction extracted and purified from $2 \mathrm{~kg}$ of barley (Fuji Nijo II) was examined by bioassay with dwarf rice seedlings. The fraction corresponding to ABA completely inhibited the growth of the rice seedlings.

The methylated derivatives of the ABA fraction were subjected to GC-MS analysis. The mass spectrum of the fraction corresponding to authentic $(2 Z, 4 E)$-ABA methyl ester was identical with those of the authentic specimen as shown in Fig. 1. These experimental results

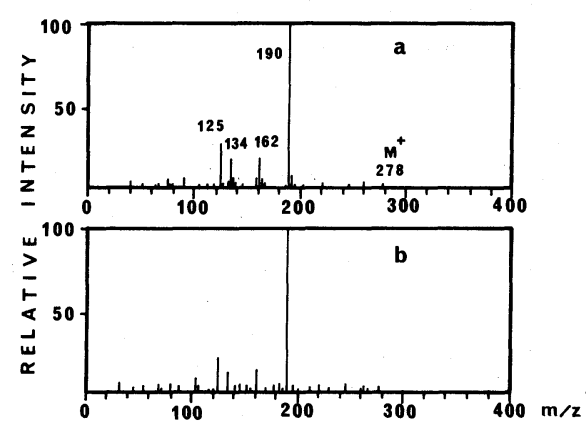

FIG. 1. Gas Chromatography-Mass Spectrometry of the Methylated Derivatives of the Fraction Corresponding to ABA Isolated and Purified from Barley.

a, mass spectrum of authentic $(2 Z, 4 E)$-ABA Me; b, mass spectrum of the methylated derivatives of the fraction corresponding to $(2 Z, 4 E)$-ABA scanned at the same retention time as the authentic specimen. 
show that $(2 Z, 4 E)$-ABA is present in barley kernels. There were some reports ${ }^{12,13)}$ on the identification of ABA in barley by analysis of its UV spectrum or by gas chromatography with an apparatus equipped with a flame ionization detector, but there seemed to be no reports in which ABA was clearly identified by mass spectrometry. On the other hand, identification of ABA in wheat or rice seeds $s^{14 \sim 18}$ ) which belong to the same family (Gramineae) as barley, was carried out by gas chromatography equipped with an electron-capture detector or by mass spectrometry.

The recoveries of added ABA at the level of 0.1 and $1 \mathrm{mg}$ to $100 \mathrm{~g}$ of barley through the extraction and purification procedures ranged from 87 to $98 \%$. Reproducibility of the determination of endogenous ABA in barley was good: $X=23.7 \mu \mathrm{g} / \mathrm{kg}(n=6)$, S.D. $=2.21$, S.D. $X \times 100=9.4$.

\section{Localization of endogenous $A B A$ in barley kernels}

After separation of the husks by abrasion, the embryo was separated from its endosperm with a razor. The levels of endogenous ABA in each part were then determined. The results are summarized in Table I. Although ABA was distributed in the husk, embryo, and endosperm, it was most abundant, per gram, in the embryo. This agrees with reports on immature barley, ${ }^{12)}$ immature wheat, ${ }^{14)}$ and beans. ${ }^{19)}$ The significance of a high level of ABA in the embryo is interesting and requires further study.

\section{Solubilization of $A B A$ in steep liquor}

Three hundred grams of barley (Fuji Nijo II) were steeped in $500 \mathrm{ml}$ of water for a prescribed period, and the ABA level of the steep liquor was determined (Fig. 2). This level greatly increased during the first $2 \mathrm{hr}$ and then reached a plateau. The degree of solubilization of ABA from barley kernels in the steep liquor was not affected by aeration, but was increased by about $25 \%$ with $0.03 \mathrm{~N} \mathrm{NaOH}$ solution. The level of ABA in the steep liquor greatly decreased with changes of the steep
TABle I. Distribution OF ABA IN BARLEY KERNELS*

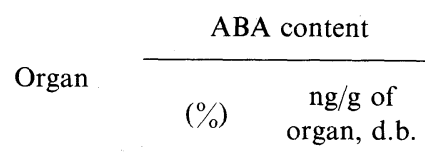

\begin{tabular}{|c|c|c|c|}
\hline \multicolumn{4}{|l|}{ Barley } \\
\hline & Embryo & 37.3 & 191.2 \\
\hline & Endosperm & 33.6 & 5.9 \\
\hline & Husk & 29.1 & 47.5 \\
\hline
\end{tabular}

Green malt

(Germinated for 4 days)

$\begin{array}{llr}\text { Rootlet } & 33.3 & 130.6 \\ \text { Acrospire } & 22.9 & 162.1 \\ \text { Embryo axis } & 22.4 & 74.7 \\ \text { Endosperm } & 11.0 & 2.8 \\ \text { Husk } & 10.4 & 16.5\end{array}$

* Fuji Nijo II barley was used.

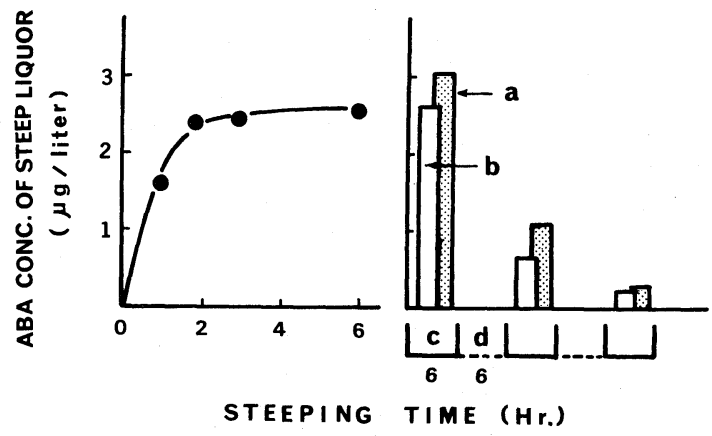

FIG. 2. Solubilization of ABA in Steep Liquor during Steeping of Barley.

$a$, steeping in $0.03 \mathrm{~N} \mathrm{NaOH}$ solution; $b$, steeping in deionized water; c, steeping in water; d, steeping in air (draining).

water. The total amount of ABA solubilized in the steep liquor after 3 changes of water every $6 \mathrm{hr}$ was $5.6 \mu \mathrm{g}$ per $\mathrm{kg}$ of barley (d.b.), which was equivalent to almost $80 \%$ of the amount contained in the husk.

The purposes of steeping barley in water at the first step of malting are to absorb enough water for germination, to wash out the dust or micro-organisms adhering to the surface of the barley, and to take off any material which would inhibit germination from the husk. ${ }^{20}$ Coumarin and several phenolic substances in husks have been considered to be inhibitors of 
germination, ${ }^{20}$ ) but this study revealed that ABA, a kind of plant hormone having an inhibitory activity toward germination, is also eliminated by solubilization from husk into the steep liquor.

Changes in the level of endogenous $A B A$ in barley kernels during steeping

During barley steeping (Fuji Nijo II, $500 \mathrm{~g} / 500 \mathrm{ml}$ of water), the level of endogenous ABA remaining in barley kernels was determined. The conditions for aeration during steeping were varied: continuous aeration, no aeration, and aeration only for the first $6 \mathrm{hr}$. The steeping water was changed every $24 \mathrm{hr}$. The results are shown in Fig. 3.

When aeration was carried out throughout the steeping period, the level of endogenous ABA in barley kernel greatly decreased and reached the level of $10 \%$ of that of unsteeped barley after $20 \mathrm{hr}$. From this point it was possible to count the germinated barley kernels. On the other hand, when the barley was steeped without aeration, the decrease in the level of ABA was slow, and no germinated kernels were observed after $70 \mathrm{hr}$. When the aeration was stopped after an initial $6 \mathrm{hr}$, the rate of decrease in the ABA level became small following a great decrease during the initial $6 \mathrm{hr}$ of steeping. The amount of ABA decreased by anaerobic steeping was almost equivalent to the level in the husk, and the amount decreased by aerobic steeping was much higher than the level of ABA solubilized from barley kernels into the steep liquor. This suggests that the barley kernel has an ABA-

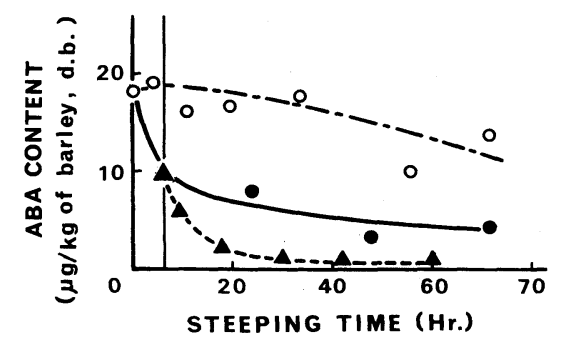

FIG. 3. Changes in the Level of Endogenous ABA in Barley during Steeping.

$\bigcirc$, anaerobic steeping;, anaerobic steeping after six $\mathrm{hr}$ of aerobic steeping; $\boldsymbol{\Delta}$, aerobic steeping. metabolizing system which is activated by an adequate supply of oxygen. As shown in Fig. 4 , the relationship between the level of ABA in barley and the percentage of germinated kernels reveals that when the level of ABA in barley kernels falls to a prescribed level, the kernel starts to germinate. Accordingly, it may be considered that ABA and its metabolizing system play an important role in initiating the germination of barley. This hypothesis may be supported by the observation of VanOnckelen et $a l .{ }^{19)}$ who showed that when immature beans were steeped in water, the level of ABA greatly decreased and then germination started.

Changes in the level of $A B A$ during the germination process and distribution of $A B A$ in germinating barley kernels

After steeping barley (Fuji Nijo II) aerobically or anaerobically under the same conditions as described in the previous section, the barley samples were germinated and the levels

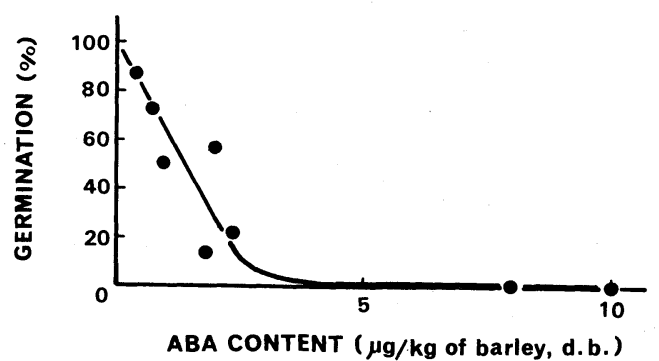

FIG. 4. Relationship between the Level of Endogenous ABA and the Percentage of Germinated Kernels.

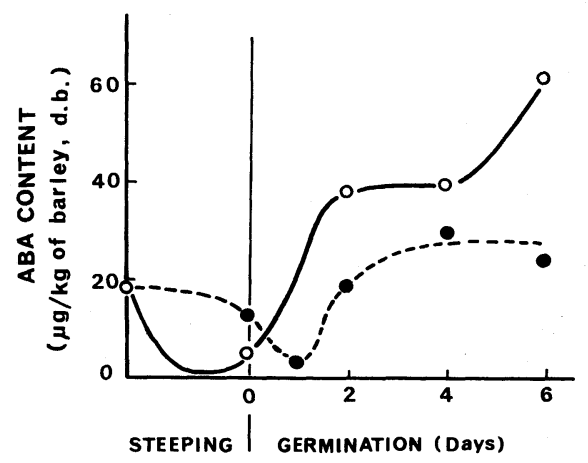

FIG. 5. Changes in the Level of Endogenous ABA in Barley during Steeping and Germination.

$\bigcirc$, aerobic steeping; $\boldsymbol{O}$, anaerobic steeping. 
of endogenous ABA were determined. The results are shown in Fig. 5. When the barley was steeped aerobically, the level of endogenous $\mathrm{ABA}$ in the barley increased during germination, especially in the later stage, after the great decrease during steeping. On the other hand, when the steeping was carried out anaerobically, the level of endogenous ABA became lowest following the small decrease during steeping, and then it started to increase. The level of ABA, however, did not reached that of aerobic steeping and the great increase in the later stage was not observed. Betzes also showed the same results.

In order to understand the significance of endogenous ABA in germinating barley, its distribution in the barley kernel was examined. Barley germinated for 4 days was divided after lyophilization into rootlets, husk, acrospire, embryo axis, and endosperm, and each part was subjected to ABA determination. The results are shown in Table $\mathrm{I}$. The concentration of ABA in growing organs such as rootlets and acrospire increased with germination, while that in the husk and endosperm decreased. This indicates that a large amount of the ABA in the husk becomes solubilized in the steep liquor and that the ABA originally present in embryo axis and endosperm might be decomposed by some metabolizing system during steeping. The endogenous ABA in rootlets, acrospire, and embryo axis may be synthesized de novo with their growth during germination. Therefore, it is necessary to study the significance of the de novo synthesis and role of ABA in rapidly growing organs al- though ABA has an inhibitory activity toward germination of barley.

\section{Effects of $A B A$ addition on malting and the quality of malt}

I previously reported that endogenous gibberellin (GA) in barley was not detected during steeping, but it reached its maximum concentrations on the second day and decreased on the fourth and sixth days of germination. ${ }^{7)}$ Accordingly, two kinds of plant hormones (ABA and GA) having opposite physiological activity are present in germinating barley kernels in some balance; and this balance gradually changes with the progress of germination, resulting in changes in malt quality. On the basis of many studies on the effect of $\mathrm{GA}_{3}$ addition during malting on malt quality, it became common practice in commercial malting to artificially change the hormone balance by adding $\mathrm{GA}_{3}$. Therefore I tried to alter the hormone balance in barley kernels by addition not only of $\mathrm{GA}_{3}$ but also of ABA to control germination and malt quality. ABA solution was sprayed alone or in combination with $\mathrm{GA}_{3}$ onto barley (Betzes) after it was steeped to a $43 \%$ moisture content. The amount of $\mathrm{ABA}$ added was $0.1,1$, or $10 \mathrm{mg}$ per $\mathrm{kg}$ of barley and that of $\mathrm{GA}_{3}$ was $0.1 \mathrm{mg}$ per $\mathrm{kg}$. The treated barley samples were malted by the prescribed method. The yield of malt and the results of the malt analysis are summarized in Table II. In spite of the addition of $\mathrm{GA}_{3}, \mathrm{ABA}$ restricted the growth of rootlets, resulting in an increase in the malt yield. The extract content was increased by an appropriate amount of ABA

Table II. EfFects of ABA plus $\mathrm{GA}_{3}$ on Malt Quality

\begin{tabular}{lccccc}
\hline Amount of $\mathrm{ABA}^{2}$ added* & 0 & 0 & 0.1 & 1 & 10 \\
Amount of $\mathrm{GA}_{3}$ added* & 0 & 0.1 & 0.1 & 0.1 & 0.1 \\
\hline Yield of malt (\%, d.b.) & 90.7 & 90.8 & 91.2 & 91.2 & 91.5 \\
Extract, fine grind (\%, d.b.) & 79.4 & 80.2 & 80.0 & 80.0 & 77.6 \\
Kolbach index (\%) & 47.6 & 51.5 & 49.7 & 40.7 & 34.8 \\
Color of wort (EBC unit) & 4.7 & 6.9 & 5.3 & 4.1 & 3.8 \\
Diastatic power & 196 & 206 & 211 & 213 & 167 \\
$\quad$ (Windisch-Kolbach unit) & 82.2 & 81.6 & 82.4 & 83.1 & 80.2 \\
Apparent attenuation limit (\%) & & & & & \\
\hline
\end{tabular}

* $\mathrm{mg} / \mathrm{kg}$ of barley (Betzes). 
plus $\mathrm{GA}_{3}$. Large increases in wort nitrogen and changes in wort color caused by $\mathrm{GA}_{3}$ were controlled by ABA. With the use of an appropriate amount of $\mathrm{ABA}$ plus $\mathrm{GA}_{3}$, the diastatic power became higher than that of the control; and the fermentability (apparent attenuation limit) of the wort was also raised. Therefore, it was found that the quality of the malt obtained by adding ABA in combination with $\mathrm{GA}_{3}$ during malting was higher than that of the malt prepared by adding $\mathrm{GA}_{3}$ alone. The same results were obtained on a 1.5 ton scale in a malting plant (data not shown).

When $\mathrm{GA}_{3}$ is used for malting, a lower malting yield due to enhanced respiration and growth of rootlets and abnormally increased wort color due to excess decomposition of protein in endosperm has been generally recognized, and potassium bromate $\left(\mathrm{KBrO}_{3}\right)$ is commonly used in western countries with $\mathrm{GA}_{3}$ to overcome these defects of $\mathrm{GA}_{3}$ treatment. ${ }^{21}$ ) However, substitutes for potassium bromate have been sought because the latter is said to be mutagenic. ${ }^{22)}$ An appropriate alternative has not been found till now. The use of ABA in malting is preferable to that of potassium bromate or other compounds, because ABA is a naturally-occurring compound and is usually present in cereal grains, vegetables, and fruits. Moreover, ABA has effects on malt quality at much lower levels than potassium bromate and other compounds. The method of malting with $\mathrm{ABA}$ and the effect of ABA on malt quality will be reported in detail elsewhere. ${ }^{23)}$

Synthetic ABA which is composed of $(+)$ ABA (natural) and (-)-ABA (artificial) is commercially available but expensive. Recently several studies on the production of $(+)$-ABA by fermentation with microorganisms are progressing well, ${ }^{24 \sim 29)}$ but the application of ABA to the brewing industry has not been made till now. This study should open the way for the industrial use of ABA produced by fermentation.

Acknowledgments. I thank Professor H. Koshimizu, of the University of Kyoto, for helpful advice, and the management of Kirin Brewery Co., Ltd. for permission to publish this work. I am grateful for the continuous encouragement of Dr. T. Inoue, Director of the Brewing Science Laboratory, and Dr. E. Kokubo, its former director.

\section{REFERENCES}

1) R. Verbeek-Wyndaele, Eur. Brew. Conv. Proc. Congr., 14th, Salzburg, 1973, p. 75.

2) A. M. MacLeod, Eur. Brew. Conv. Proc. Congr., 16th, Amsterdam, 1977, p. 63.

3) A. M. MacLeod, Wallerstain Lab. Commun., 30, 85 (1967).

4) G. H. Palmer, J. Inst. Brew., 80, 13 (1974).

5) H. Yomo, Hakko Kyokaishi, 16, 444 (1958).

6) L. G. Paleg, Plant Physiol., 35, 293, 902 (1960).

7) K. Yamada, J. Am. Soc. Brew. Chem., 40, 18 (1982).

8) T. Yoshida, K. Yamada, S. Fujino and J. Koumegawa, J. Am. Soc. Brew. Chem., 37, 77 (1979).

9) S. D. Seeley and L. E. Powell, Anal. Biochem., 35, 530 (1970).

10) European Brewery Convention, Analytica-EBC, 2nd Ed., Elsevier Publ. Co., Amsterdam, 1963, p. 14.

11) H. Murakami, Shokubutsu Seiri, 4, 189 (1965).

12) H. Goldbach and G. Michael, Crop. Sci., 16, 797 (1976).

13) B. Slominski and A. Rejowski, Physiol. Plant, 45, 167 (1979).

14) R. W. King, Planta, 132, 43 (1976).

15) J. A. McWha, J. Exp. Bot., 26, 823 (1975).

16) M. Radley, J. Exp. Bot., 27, 1009 (1976).

17) T. Oritani and T. Oritani, Proc. Crop. Sci. Soc. Jpn., 40, 34 (1971).

18) Y. Suzuki, S. Kurogochi, N. Murofushi, Y. Ota and N. Takahashi, Plant Cell Physiol., 22, 1085 (1981).

19) H. VanOckelen, R. Caubergs, S. Horemans and J. A. DeGreef, J. Exp. Bot., 31, 913 (1980).

20) G. Harris, "Barley and Malt," ed. by A. H. Cook, Academic Press Inc., New York and London, 1962, pp. $276,560$.

21) A. Macey and K. C. Stowell, Eur. Brew. Conv. Proc. Congr., 8th, Vienna, 1961, p. 85.

22) Y. Kurokawa, Y. Hayashi, A. Maekawa, M. Takahashi and T. Kokubo, Gann, 7, 335 (1982).

23) K. Yamada, J. Am. Soc. Brew. Chem., 42, 79 (1984).

24) G. Assante, L. Merlini and G. Nashini, Experientia, 33, 1556 (1977).

25) S. M. Norman, V. P. Maier and L. C. Echols, Appl. Environ. Microbiol., 41, 981 (1981).

26) K. Araki, H. Yoshida and T. Takayama, Japanese Patent, 56-160996.

27) K. Araki and T. Takayama, Japanese Patent, 5836393.

28) S. Marumo, Japanese Patent, 58-51895.

29) E. Kouno, H. Hayashi, T. Kimoto, M. Natsume and S. Marumo, Abstract of Papers, Annual Meeting of Nippon Nôgeikagaku Kai, Tokyo, April, 1984, p. 298. 